\title{
Clinical trial registration - the global landscape
}

\author{
Udaya K. Ranawaka ${ }^{1}$ \\ Journal of the Ceylon College of Physicians, 2021, 52, 8-12
}

Key words: clinical trials; clinical trial registration; clinical trials registry; Sri Lanka Clinical Trials Registry

Medicine has advanced by leaps and bounds over the last few centuries. New diseases have been identified, new diagnostic techniques developed, and new treatments discovered in our continuous quest to alleviate human suffering. Yet, new pathogens and new diseases keep on emerging, challenging our capacity to develop effective treatments capable of controlling or curing them, a point best exemplified on a global scale by the current COVID-19 pandemic caused by the SARS-CoV-2 virus. And as repeatedly highlighted by our rushed and failed attempts to find an effective treatment for the pandemic, anecdotal reports of benefit of a given treatment can no longer be considered valid, and the balance of therapeutic benefit over harm of any new intervention must be demonstrated in a properly conducted clinical trial.

\section{Clinical trials - the good, the bad, and .....}

From the first modern day clinical trial of oranges and lemons for sailors with scurvy on a ship by the surgeon James Lind in 1747, the first double-blind trial of Penicillium patulinum extract for common cold in 1943, and the first randomised controlled trial of streptomycin for tuberculosis in $1948,,^{1,2,3}$ clinical trials have evolved with increasing sophistication of methodology to ensure generation of valid, reliable and reproducible results. The randomised controlled trial is now considered the best research method for evaluating the efficacy and safety of a new intervention, and modern-day treatment guidelines are based on systematic reviews and meta-analyses of such randomised trials. To put it simply, clinical trials form the bedrock of evidence needed for everyday clinical decision-making.

However, all is not rosy in the world of clinical trials. Research misconduct of many types has, to some extent, eroded the blind faith placed on the evidence generated by clinical trials; selective reporting of results is an important one among these. Firstly, results of all trials do not get published. Only about half of over a million controlled trials conducted since the landmark trial of streptomycin have been published, and at least one-third of all trials have not been indexed in Medline, the main source of evidence for many investigators and clinicians; ${ }^{4}$ thus, the results of a large number of trials remain hidden from the public view. Importantly, 'negative' trials with inconclusive results or results suggesting a possible harm associated with the intervention are the ones more likely not to publish their results. ${ }^{5,6,7}$ On the other hand, 'positive' trials with results supporting a new intervention are sometimes published twice, or even several times. ${ }^{8}$ This selective reporting leads to distortion of the available evidence, with exaggeration of benefits and concealment of potential harm. ${ }^{9}$

Prospective registration of all clinical trials was proposed in the 1970's as a possible mechanism to mitigate the harmful effects of selective reporting. ${ }^{10,11}$ For many years, it remained only a noble concept and an ideal worth pursuing, until several high-profile reports of therapeutic misadventure related to concealment of potential harm of new drugs ${ }^{5,6,7}$ led to an international outcry and forced the scientific community to wake up to the realities of the clinical trial world.

\footnotetext{
${ }^{1}$ Professor in Neurology, Faculty of Medicine, University of Kelaniya; Administrator, Sri Lanka Clinical Trials Registry, Sri Lanka.
}

Correspondence: E-mail: udayaran@yahoo.com; udayaran@kln.ac.Ik

https://orcid.org/0000-0002-4050-062X

Received 18 April 2021, accepted 15 May 2021.

This is an open-access article distributed under the terms of the Creative Commons Attribution License, which permits unrestricted use, distribution, and reproduction in any medium, provided the original author and source are credited. 


\section{The road to clinical trial registration}

Several disease-specific (e.g., cancer), countryspecific (in several European countries), regional and international trial registers were operational from the 1970s, but there was no collective international effort to ensure adherence to universal trial registration. The first milestone on the path to mandatory clinical trial registration was a strong collaborative statement by the International Committee of Medical Journal Editors (ICMJE) in September 2004 that all clinical trials involving human subjects should be prospectively registered before they can be considered for publication. ${ }^{9}$ The World Health Assembly in May 2005 supported this stance with a resolution requesting the World Health Organization (WHO) to develop a common platform for clinical trials registers. ${ }^{12}$ This led to the establishment of the International Clinical Trials Registry Platform (ICTRP) by the WHO in May 2006, with the WHO declaring that 'registration of all interventional trials is a scientific, ethical and moral responsibility'.13,14 In October 2008, the $59^{\text {th }}$ World Medical Association General Assembly amended the Declaration of Helsinki, the statement of ethical principles that provides guidance on the conduct of medical research involving human subjects, with the revision that 'every clinical trial must be registered in a publicly accessible database before recruitment of the first subject'. ${ }^{15}$

\section{Why register trials?}

Prospective trial registration has many benefits for patients, clinicians, researchers, health care planners and the public. Clinical decisions should be based on all the available evidence, and selective reporting undermines this process and may result in potential harm to patients. Free access to data from all the clinical trials of a given intervention in an easily accessible public domain, i.e., a clinical trial registry, would lead to better decision-making and improved patient care. Patients and healthy volunteers participate in clinical trials with the altruistic expectation that the research would advance medical knowledge, even if they may not stand to gain personal benefit. Failure to disclose results of such trials is a breach of the covenant of trust between researchers and participants, and is considered scientific misconduct. Knowledge of completed trials with unpublished results, and of trials currently conducted in different parts of the world, would enable researchers, funding agencies and policymakers to minimise duplication of research work and wastage of scarce resources. It would also help in identifying important gaps in research areas and facilitate regional and international research collaborations. Awareness of trials being conducted on specific diseases would help clinicians to encourage patient participation in clinical trials. Trial registration data would also provide a clear overview of the clinical trial landscape at a national or regional level.

\section{Clinical trial registration - the global landscape}

The ICTRP was established under the auspices of the WHO to create a global mechanism 'to ensure that a complete view of research is accessible to all those involved in health care decision making'.13 It has a network of registries that provides data on clinical trials conducted worldwide, which are easily accessible via the ICTRP Search Portal. The Registry Network consists of Primary Registries and Partner Registries that fulfil stringent WHO criteria for content, accessibility, data quality, technical capacity and administrative structure. Primary Registries differ from Partner Registries in that they have a national or regional remit, are managed by a not-for-profit organisation, are open to all prospective registrants, accept trials on any disease condition or intervention, and provide data directly to the ICTRP. Currently (as of February 2021) there are 17 Primary Registries in the Registry Network. The ICTRP has introduced a minimum 24item trial registration data set (TRDS) to ensure uniformity of data collection by different registries, and a universal Trial number (UTN) which is a unique trial identifier that will enable unambiguous identification of trials that may be registered across several registries. Primary registries are regularly audited by the ICTRP to ensure their continued adherence to the international standards for trial registration specified by the ICTRP. The ICTRP Search Portal is a one-stop source for data on clinical trials conducted worldwide.

\section{Clinical trial registration in Sri Lanka}

Sri Lanka, in spite of its small size, resource constraints, low health care expenditure and a very small volume of clinical trials being conducted, was one of the first countries to join the global effort in clinical trial registration. The Sri Lanka Clinical Trials Registry (SLCTR) was established in November 2006 and was the first clinical trials registry in South Asia and from a resource-limited country to commence operations. The SLCTR was recognized as a Primary Registry by the WHO-ICTRP in March 2008, being the fourth Primary Registry to join the Registry Network. ${ }^{16,17}$

The SLCTR (http://www.slctr.lk/) is an internetbased, not-for-profit clinical trials registry, with free access to researchers, clinicians, policy makers, funding agencies and the public. It is a repository for trials conducted in Sri Lanka and overseas. Trial data 
from the SLCTR are regularly uploaded to the ICTRP and can be accessed via the ICTRP Clinical Trials Search Portal. The SLCTR has evolved over the years in a constant endeavour to meet the stringent standards laid down by the ICTRP, despite the many challenges posed by resource constraints inherent to a low-middle income country. The SLCTR has regularly contributed to the global literature on clinical trial registration; its progress has been well documented in the early years, ${ }^{18,19}$ and it was the first to report the ten-year experience of a primary clinical trial registry. ${ }^{20}$ While meeting its key obligation of providing a national platform for clinical trial registration, it has carried out many activities to improve awareness on trial registration and enhance research capacity at a national level. The Ministry of Health has supported the SLCTR from its inception and has recognised the SLCTR as the national body for clinical trial registration. The guidelines for the conduct of clinical trials in Sri Lanka issued by the Ministry of Health state that registering the study in the SLCTR is a prerequisite for the conduct of a clinical trial in Sri Lanka. ${ }^{21}$

\section{Clinical trial registration - challenges and progress}

Even after a decade of mandatory trial registration, the global campaign for trial registration continues to face numerous challenges. Firstly, many trials are still conducted and published without being registered in a publicly accessible registry. In a study of 318 trials for evaluation of new drugs approved by the US Food and Drug Administration (FDA) in 2012, only $57 \%$ had been registered. ${ }^{22}$ In a 2013 survey of randomised controlled trials published in PubMed indexed journals, only 53\% were registered. ${ }^{23}$ Publishing journals too may have contributed to this unhealthy state of affairs; in a 2013 survey of 200 medical journals, only $28 \%$ specified trial registration as a requirement in their author guidelines. ${ }^{24}$ Although prospective trial registration is the international requirement, many trials continue to be registered retrospectively, i.e after recruitment of the first participant. Retrospective registration undermines the core principle of trial registration, that of ensuring complete transparency in the conduct of clinical trials. Over two-thirds of all clinical trials published in a series of open access, peer-reviewed medical journals were retrospective trial registrations. ${ }^{25}$ In a survey of several clinical trial registries, over half of the trial records were registered retrospectively. ${ }^{26}$

Investigators still remain unenthusiastic about registering their trials. A survey conducted in 2017 among trialists revealed that only $21 \%$ of respondents had registered all their trials, and less than half were willing to provide all the trial data required by the WHO in future trials; this was especially true for investigators receiving funding from the pharmaceutical industry. ${ }^{27}$ Lack of knowledge on the international requirements for trial registration is also an important cause for the low rates of trial registration. ${ }^{27,28}$ Many inadequacies in awareness on various aspects of trial registration among researchers has been previously highlighted. ${ }^{29}$ Quality of trial registration data continues to be a major problem. Several studies have documented the poor quality of trial registration data in the primary registries belonging to the ICTRP Registry Network, and the lack of improvement of data quality over time. ${ }^{26,30,31}$

In spite of these challenges, the concept of prospective clinical trial registration has gradually gained acceptance from the scientific community, and the pharmaceutical industry which sponsors many of the clinical trials and provided much of the initial resistance to trial registration. The number of clinical trials registered worldwide has increased five-fold from 2004 to 2013 . $^{32}$ Data from one of the primary registries of the ICTRP network has shown that the compliance with prospective registration had increased from $48 \%$ in 2006 to $63 \%$ in $2012 .{ }^{28}$ The challenges posed by the COIVD-19 pandemic, which has brought the international scientific community together in the face of global adversity, showcased the global worth of an existing international mechanism for trial registration. The ICTRP developed a separate web portal in response to the ever-increasing demand from COIVD-19 related trial registrations, and at the time of writing (February 2021), over 8000 trials have been registered with the database. In a rapidly changing scenario such as the COIVD-19 pandemic, the ability of the scientific community to gather data from such a staggering number of clinical trials conducted across the world at a single point of access would have greatly facilitated research into new treatments and vaccines.

\section{The road ahead}

Clarion calls are being sounded for increasing transparency in the conduct and publication of clinical trials. It was more than a decade ago that the Ottawa statement argued for the inclusion of trial protocols at the time of initial trial registration and of summary results following trial completion. ${ }^{33}$ Many indexed journals have started publishing trial protocols, and this is a step in the right direction towards making all trial protocols publicly accessible. The WHO in 2015 made a policy statement calling for public disclosure of all clinical trial results ${ }^{34,35}$. The ICMJE in 2016 proposed full public disclosure of all participant data in clinical trials, which has not gained uniform acceptance by trial investigators and has led to a vigorous debate on the amount of trial details that can 
be divulged without compromising the academic interests of the researchers and the financial interests of the pharmaceutical industry that develops new interventions. ${ }^{36,37,38,39}$

Clinical trial registration has undoubtedly been a significant milestone on the road to a more open and transparent world of clinical research. Within a short time span, it has been embraced by the scientific community and has been a key driver for change in the global research landscape. Many shortcomings still exist in the mechanisms available for trial registration, and many challenges lie ahead. The ultimate goal is to have all the data from all the trials freely available to all the people all over the world. We are still a long way from getting there.

\section{References}

1. Chalmers I, Milne I, Trohler U, Vandenbroucke J, Morabia A, Tait G, Dukan E; The James Lind Library editorial team. The James Lind Library: explaining and illustrating the evolution of fair tests of medical treatments. J R Coll Physicians Edinb. 2008; 38: 259-64.

2. Collier R. Legumes, lemons and streptomycin: a short history of the clinical trial. CMAJ 2009; 180(1): 23-4. doi: 10.1503/ cmaj.081879

3. Bhatt A. Evolution of clinical research: a history before and beyond James Lind. Perspect Clin Res. 2010; 1(1): 6-10.

4. Dickersin K, Rennie D. Registering clinical trials. Journal of the American Medical Association 2003; 290: 516-23.

5. Teo KK, Yusuf S, Furberg CD. Effects of prophylactic antiarrhythmic drug therapy in acute myocardial infarction: an overview of results from randomized controlled trials. Journal of the American Medical Association 1993; 270 : 1589-95.

6. Whittington $\mathrm{CJ}$, Kendall $\mathrm{T}$, Fonagy $\mathrm{P}$, et al. Selective serotonin reuptake inhibitors in childhood depression: systematic review of published versus unpublished data. Lancet 2004; 363: 1341-5.

7. Curfman GD, Morrissey S, Drazen JM. Expression of concern: Bombardier et al., "Comparison of upper gastrointestinal toxicity of rofecoxib and naproxen in patients with rheumatoid arthritis," N Engl J Med 2000; 343: 1520-8. N Engl J Med. 2005; 353(26): 2813-4. doi: 10.1056/ NEJMe058314.

8. Gotzsche PC. Multiple publication of reports of drug trials. European Journal of Clinical Pharmacology 1989; 36: 429-32.

9. DeAngelis C, Drazen JM, Frizelle FA, Haud C, Hoey J, Horton R. Clinical trial registration: a statement from the International Committee of Medical Journal Editors. N Engl J Med 2004; 351: 1250-1. doi:10.1056/NEJMe048225.
10. Chalmers TC. Randomize the first patient! N Engl J Med 1977; 296: 107.

11. Simes RJ. Publication bias: the case for an international registry of clinical trials. Journal of Clinical Oncology 1986; 4: 1529-41.

12. World Health Organization. Fifty-eighth World Health Assembly: Resolutions and decisions (WHA58/2005/REC/ 1). World Health Organization, Geneva; 2005. http:// apps.who.int/gb/ebwha/pdf_files/WHA58-REC1/english/ A58_2005_REC1-en.pdf

13. WHO. International Clinical Trials Registry Platform. https:// www.who.int/clinical-trials-registry-platform.

14. Humphreys G. Giving patients better access to trial information. Bulletin of the World Health Organization 2006; 84: 429-31.

15. World Medical Association. Declaration of Helsinki. World Medical Association, Seoul; 2008. http://www.wma.net/en/ 30publications/10policies/b3/17c.pdf17c.pdf

16. Ranawaka UK, Goonaratna C. Sri Lanka Clinical Trials Registry. Ceylon Med J 2007; 52: 117-9.

17. Ranawaka UK, Goonaratna C. Establishing the Sri Lanka Clinical Trials Registry. J Evid Based Med 2009; 2: 29-31.

18. Ranawaka UK, Wanigatunga C, de AbrewA, Wimalachandra M, Goonaratna C. The Sri Lanka Clinical Trials Registry five years young, and growing. Ceylon Med J 2012; 57 : 95-6.

19. Ranawaka UK, Goonaratna C. The Sri Lanka Clinical Trials Registry - Moving forward. J Evid Based Med 2011; 4(3): 179-81.

20. Ranawaka UK, de Abrew A, Wimalachandra M, Samaranayake N, Goonaratna C. Ten years of clinical trial registration in a resource-limited setting: Experience of the Sri Lanka Clinical Trials Registry. J Evid Based Med 2018; 11: 46-50. doi: 10.1111/jebm.12284.

21. National Medicine Regulatory Authority, Ministry of Health, Sri Lanka. Guidelines for the conduct of clinical trials in Sri Lanka. Ministry of Health, Colombo; October 2019. https:// nmra.gov.Ik/images/PDF/guideline/Guideline-for-the-conductof-Clinical-Trials-in-Sri-Lanka.pdf

22. Miller JE, Korn D, Ross JS. Clinical trial registration, reporting, publication and FDAAA compliance: a cross-sectional analysis and ranking of new drugs approved by the FDA in 2012. BMJ Open 2015; 5(11): e009758. doi: 10.1136/ bmjopen-2015-009758

23. Odutayo A, Emdin CA, Hsiao AJ, Shakir M, Copsey B, Dutton S, Chiocchia V, Schlussel M, Dutton P, Roberts C, Altman DG, Hopewell S. Association between trial registration and positive study findings: cross sectional study (Epidemiological Study of Randomized Trials-ESORT). BMJ 2017; 356: j917. doi: 10.1136/bmj.j917.

24. Wager E, Williams P. Project overcome failure to publish negative findings consortium. "Hardly worth the effort"? 
Medical journals' policies and their editors' and publishers' views on trial registration and publication bias: quantitative and qualitative study. BMJ 2013; 347: f5248. doi: 10.1136/ bmj.f5248.

25. Harriman SL, Patel J. When are clinical trials registered? An analysis of prospective versus retrospective registration. Trials 2016; 17: 187. doi: 10.1186/s13063-016-1310-8.

26. Viergever RF, Ghersi D. The Quality of Registration of Clinical Trials. PLoS ONE 2011; 6: 2: e14701. doi:10.1371/ journal.pone.0014701.

27. Reveiz L, Krleza-Jeric K, Chan AW, De Aguiar S. Do trialists endorse clinical trial registration? Survey of a Pubmed sample. Trials 2007; 8: 30.

28. Hunter KE, Seidler AL, Askie LM. Prospective registration trends, reasons for retrospective registration and mechanisms to increase prospective registration compliance: descriptive analysis and survey. BMJ Open 2018; 8(3): e019983. doi: 10.1136/bmjopen-2017-019983.

29. Ranawaka UK, deAbrewA, Wimalachandra M, Wanigatunge CA, Rajapakse LC, Goonaratna C. Awareness of clinical trial registration among healthcare professionals: An observational study. J Evid Based Med. 2018; 11(4): 227-32. doi: 10.1111/jebm.12327.

30. Viergever RF, Karam G, Reis A, Ghersi D. The quality of registration of clinical trials: still a problem. PLOS ONE 2014; 9: 1: e84727.

31. Sekeres M, Gold JL, Chan AW, Lexchin J, Moher D, Van Laethem ML, Maskalyk J, Ferris L, Taback N, Rochon PA. Poor reporting of scientific leadership information in clinical trial registers. PLoS One. 2008; 3(2): e1610. doi: 10.1371/ journal.pone.0001610.
32. Viergever RF, Li K. Trends in global clinical trial registration: an analysis of numbers of registered clinical trials in different parts of the world from 2004 to 2013. BMJ Open 2015; 5: e008932. doi: 10.1136/bmjopen-2015-008932.

33. Krleza-Jeric K, Chan AW, Dickersin K, Sim I, Grimshaw J, Gluud C, (for the Ottawa group): Principles for international registration of protocol information and results from human trials of health related interventions: Ottawa statement (part 1). BMJ 2005; 330: 956-58. doi:10.1136/bmj.330.7497.956.

34. World Health Organization. WHO Statement on Public Disclosure of Clinical Trial Results. Accessed 14 April 2015.

35. Moorthy VS, Karam G, Vannice KS, Kieny MP. Rationale for WHO's new position calling for prompt reporting and public disclosure of interventional clinical trial results. PLOS Med. 201514; 12(4): e1001819. doi: 10.1371/journal. pmed. 1001819

36. Taichman DB, Backus J, Baethge C, Bauchner H, de Leeuw PW, Drazen JM, Fletcher J, Frizelle FA, Groves T, Haileamlak A, James A, Laine C, Peiperl L, Pinborg A, Sahni P, Wu S. Sharing Clinical Trial Data - AProposal from the International Committee of Medical Journal Editors. N Engl J Med. 2016; 374(4): 384-6. doi: 10.1056/NEJMe1515172.

37. Bauchner H, Golub RM, Fontanarosa PB. Data Sharing: An Ethical and Scientific Imperative. JAMA 2016; 315(12): 1237-9. doi: 10.1001/jama.2016.2420.

38. Haug CJ. Whose Data Are They Anyway? Can a Patient Perspective Advance the Data-Sharing Debate? N Engl J Med. 2017; 376(23): 2203-5. doi: 10.1056/NEJMp1704485.

39. Strom BL, Buyse ME, Hughes J, Knoppers BM. Data Sharing - Is the Juice Worth the Squeeze? N Engl J Med. 2016; 375(17): 1608-1609. doi: 10.1056/NEJMp1610336 